\title{
Sarah Kantor
}

\section{Reference speed dating \\ Creating a spark at the reference desk}

$\mathbf{R}$

eference services, whether face-to-

face or virtual, have been and remain a core library service. The importance of reference services is reflected in the library and information science (LIS) curriculum, but it is often overlooked in continuing education opportunities for librarians. In both master's degree programs and the few continuing education offerings for reference services, instructors generally focus on the reference interview. For many working librarians, this can feel rote and ineffectual. After all, they already learned this in school. Experienced librarians may also feel that the reference interview is old hat, while newer librarians would benefit more from real-world practice than a repeat of their reference class.

In this speed dating-inspired workshop, we concentrated on approachability at the reference desk rather than accuracy to help reference providers fall in love with reference all over again. Our objective in focusing on approachability was twofold: to create an environment where patrons would want to return to the reference desk, and to ensure that our librarians were comfortable providing reference services.

\section{The problem with reference instruction}

Reference courses are a key part of LIS curricula, but taking a reference class does not mean that the newly graduated librarian has the skills required for the reference desk. Although there is a consensus in the field that the reference interview is important, there is no surefire way to teach the skills needed to master the reference interaction.

Most of the literature about methods for teaching reference focuses on using classroom roleplay, ${ }^{1}$ followed by a critique from the instructor and/or fellow students. ${ }^{2}$ However, in teaching reference through roleplay, students often approach the interaction more casually than they would a real-world transaction. ${ }^{3}$ Due to the lack of urgency inherent in roleplay, students may find themselves ill-prepared for reference services in the field.

Librarians and paraprofessionals may receive on-the-job training through a combination of observing and then being observed until they are "ready" to be provide reference alone. Once a new employee is deemed able to work the desk alone, they may not receive any additional training until they start a new position elsewhere. The burden for improvement is usually placed on the reference provider, rather than on supervisors or administrators, and requires that librarians be aware of their need to improve their skills.

Sarah Kantor, formerly of Kennesaw State University, is now studio librarian at University of TennesseeChattanooga Library, email: sarah-kantor@utc.edu

(c) 2020 Sarah Kantor 
This approach to professional development can create an environment where staff at the same library provide different and inconsistent reference services. There are also few professional development opportunities for reference skills available. The rare webinars and workshops offered generally follow the instruction methods used in LIS programs and focus either on the steps of the reference interview or on accuracy, so only the most dedicated reference librarian is likely to seek them out. But what if we treat answers to reference questions like dating and recognize that there are always more fish in the sea? If reference providers focus on creating an atmosphere where patrons will return to the desk, we can improve patron satisfaction and create repeat patrons.

\section{Speed dating at the reference desk}

In an effort to create an opportunity to support both new and veteran librarians in developing their reference skills, a team from the Research and Instructional Services unit at the Kennesaw State University Library System (KSU) developed a reference workshop based on speed dating.

KSU already used a combination of shadowing and observation to prepare new librarians for reference, but in mid-2018 we were tasked with finding additional ways to support our librarians after they completed the shadowing program.

At the beginning of the fall 2018 semester, we offered a workshop on the reference interview and basic reference skills. Although the feedback we received was generally positive, several librarians expressed concerns about providing accurate answers. One identified the source of her concerns as a lack of self-confidence. Based on this feedback, our team decided to create a workshop that would help librarians feel more confident in their abilities while also avoiding the artificiality of the traditional method of roleplay and feedback.

To meet these goals, we decided to use self-evaluations to help our librarians build their self-confidence and avoid the potential

\section{But what if we treat answers to refer- ence questions like dating and recog- nize that there are always more fish in the sea? If reference providers fo- cus on creating an atmosphere where patrons will return to the desk, we can improve patron satisfaction and create repeat patrons.}

embarrassment of performing and receiving critiques from a group. We also focused on step one of the reference interview: approachability. While much of the literature about reference services focuses on finding the patron's "correct" answer, we wanted to create an environment in which a librarian and patron could feel a spark that might develop into a research relationship. To meet these goals, our team looked to speed dating.

Speed dating, which was invented in 1998, pairs participants on a series of 10 to 25 "dates," each shorter than five minutes. ${ }^{4}$ Adapting speed dating to library services is not new, although it is usually aimed at patrons. Libraries have used the speed dating approach to help citizens find community leaders and elected officials, ${ }^{5}$ to help high schoolers pick books to read for pleasure, ${ }^{6}$ and to create relationships between international and domestic college students. ${ }^{7}$ We decided to use it to create an opportunity for librarians to practice answering real-life reference questions. Unlike more traditional speed dating events, our workshop had fewer "dates," allowing librarians to spend more time with "patrons."

Our team mined KSU's reference transactions to come with questions on a variety of topics, using different types of knowledge. We organized our questions into four categories, with between four and eight questions per category. We included both the patron's original question and their actual reference need, since the two are usually very different, as well as any relevant information to help the team member "get into character" when playing the patron. Since we were unable to 
completely divorce the workshop from any form of roleplay, we found that these steps helped give the interaction the sense of urgency that Laura Saunders found necessary. Because the "students" were not expected to make up a question on the fly, both parties could treat it more like a real-world reference transaction.

On the day of the workshop, we set up four stations based on the types of questions we gathered: institutional knowledge ("How do I print from a laptop?"), a beginning researcher with a vague topic ("Do you have any books about the Black Death?"), a beginning researcher with a more developed topic ("How can police be better prepared for domestic violence calls?"), and a knowledgeable researcher with an advanced topic ("I need help finding

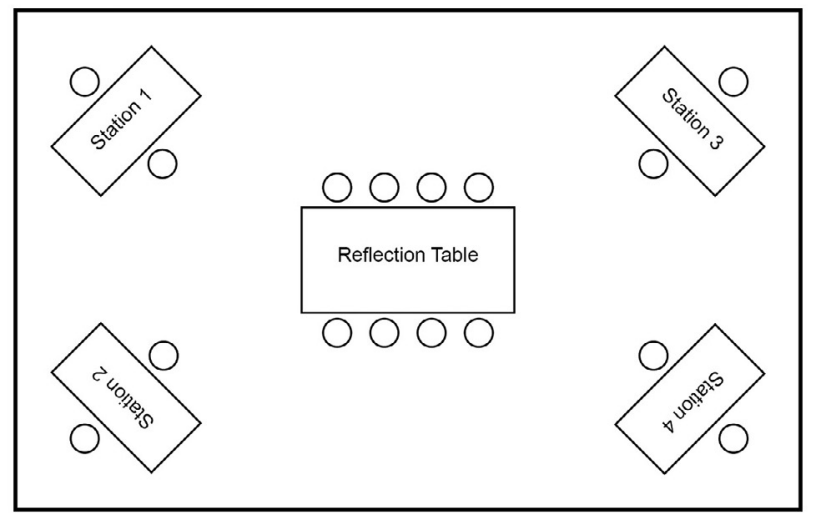

Figure 1. The room setup during the workshop. action, not necessarily to give the student the most correct answer to their question. She also explained that participants would not receive feedback from the group. They would fill out self-evaluation forms instead, allowing them reflect on their reference transactions without being critiqued in front of the group.

Participants then chose a station while the students milled around the room, waiting for a librarian to reach out to them. The workshop participants would need to focus on the approachability part of the reference interview to draw students to their primary source

documents to track a shift in political party affiliation from Reconstruction to the 1960s").

Each station had a time limit based on the depth of the question. Institutional knowledge and vague topics had a five-minute limit, while the other stations had a tenminute limit. We also provided a large table in the center of the room for participants to complete their self-evaluation forms (Figure 1). These forms took the place of feedback from the group. Members of the planning team and library staff members acted as students, while workshop participants played the librarian at the desk.

After a brief refresher on the reference interview, the workshop leader explained that the goal of the day was to get patrons to come back to the reference desk by being friendly and engaged throughout the inter- station. Once the students approached the desk, they pulled a question from a basket on the table to begin their reference transaction. The librarian would help the student find a resource to help answer the question, keeping in mind that the goal was for the student to feel comfortable enough to come back in the future. Once the student felt the question was answered, the librarian left the station, completed the self-assessment form, and then went to a new station for more practice.

Our workshop differed from traditional reference education in two main ways. First, just as the goal of speed dating is to find The One, whether that is a romantic partner or a new book, traditional reference professional development has centered on improving accuracy. We wanted to build a relationship between the patron and the library, rather than find the "one" answer to a question. By focusing on approachability at the reference desk, we can create an environment where patrons are more likely to be library users 
throughout their academic careers. We also found that centering our workshop on approachability, not accuracy, better supported our institutional reference philosophy of teaching students to find answers, not providing answers to their questions.

Our workshop also differed from traditional reference education by featuring guided self-reflection rather than feedback from the other attendees. After the workshop participants completed their turn as a librarian, they left the reference station and moved to a table in the center of the room to fill out a self-evaluation form, rating their verbal and nonverbal behaviors.

Due to the design of the room and the nature of the workshop, some of the roleplays could be observed by others. Participants were explicitly asked to not give feedback (positive or negative) on how the librarian handled the transaction. The point of the workshop was not to critique our colleagues, but to encourage everyone to reflect on their own work and motivate themselves to continue to improve their reference skills, particularly approachability.

\section{Conclusion}

After the workshop, a feedback form found that most participants learned something from the workshop. All attendees, both early-career and experienced librarians, appreciated the opportunity to practice their reference skills away from the desk. More importantly to the planning team, they felt more confident in their reference abilities.

After our reference workshop earlier that semester, several librarians had requested more reference training due to a lack of self-confidence. After the speed dating workshop, most attendees felt more confident in their reference abilities, and were more comfortable answering questions in a variety of categories. Workshop participants found their confidence increased because they felt less pressure to find the "right" answer for a patron, and were better able to focus on the personal element of the reference transaction. Recent hires especially felt more confident answering institutionspecific questions.

Without tracking patrons' reference use, we cannot say with certainty that we increased our rate of return patrons, but we did create a group of librarians who recognize that accuracy is not the only way to determine reference success. Finding the correct answer to a question is important, but a patron is unlikely to return to the reference desk if the librarian was not friendly, approachable, or engaged, regardless of how correct their answer was. By focusing on creating return patrons, we are able to help more patrons find a love of learning that we hope will stay with them long after they graduate.

\section{Notes}

1. Laura Saunders and Tien Ung, "Striving for Success in the Reference Interview: A Case Study," The Reference Librarian 58, no. 1 (2017): 50.

2. Edward J. Jennerich and Elaine Zaremba Jennerich, "Teaching the Reference Interview," Journal of Education for Librarianship 17, no. 2 (1976): 108.

3. Laura Saunders, "Teaching the Reference Interview through Practice-Based Assignments," Reference Services Review 44, no. 3 (2016): 406.

4. Eli J. Finkel and Paul W. Eastwick, "Speed-Dating," Current Directions in Psychological Science 17, no. 3 (2008): 193-97, https://www.jstor.org/stable/20183280.

5. Emily Udell, "Lawmaker Matchmaker," American Libraries magazine, last modified January 2, 2019, https://americanlibrariesmagazine.org/2019/01/02/speed-repping -lawmaker-matchmaker/.

6. Karin Greenberg, "Speed Dating with Nonfiction Books," Knowledge Quest (blog), November 27, 2018, https://knowledgequest. aasl.org/speed-dating-with-nonfiction-books/.

7. Bebe Chang, Ben Hall, and Xiang Li, "Speed Friending," Programming Librarian (blog), December 19, 2016, www. programminglibrarian.org/programs /speed-friending. $\approx$ 